\title{
MANAGEMENT OF ZIKA OUTBREAK IN A TROPICAL URBANISED COUNTRY: SINGAPORE
}

\author{
DOREEN TAN SOEK CHIN \& CHONG SI JACK \\ Department of Emergency Preparedness, Sengkang Health, Singapore.
}

\begin{abstract}
Zika is a vector borne viral disease that has been associated with significant congenital abnormalities, including microcephaly. Singapore, being a densely populated tropical country, is extremely concerned with this particular disease as the vector Aedes Egypti is endemic in the country. In Aug 2016, a local Zika outbreak occurred in Singapore, which resulted in more than 400 locally transmitted cases. The authors would like to share our experiences and lessons learnt in our acute care hospital's response to this outbreak. We will include the preparation of infrastructure, facilities, logistics, communications, screening and management procedures that allowed us to manage the outbreak expeditiously.

Keywords: aedes Aegypti, outbreak management, Singapore, vector-borne disease, zika, zika virus infection.
\end{abstract}

\section{INTRODUCTION}

Sengkang Health (SKH) is a relatively new Public Healthcare Institution (PHI), which operates from Alexandra Hospital (AH), in the south-western part of Singapore. Although SKH is considered an acute PHI [1], the hospital's bed occupancy rate stands at an average of 56\% daily, because of (a) the presence of two other major acute hospitals within the vicinity, and (b) AH being only the holding grounds for SKH, while the new SKH building is being built in the north-eastern part of Singapore.

From as early as January 2016, Singapore's Ministry of Health (MOH) and Infectious Diseases experts in the country had alerted that it was a matter of time that Singapore would face the first case of Zika virus, which was already spreading rapidly throughout Latin America [2, 3], due to the presence of the vector Aedes Aegypti in the country.

On 27 August 2016 (Saturday), MOH and the National Environment Agency (NEA) issued a joint press release $[4,5]$ to announce the first locally transmitted case of Zika virus infection. The patient, a 47-year-old female Malaysian who resides at Aljunied Crescent (south-eastern part of the island) and works in Singapore, had not travelled to Zika-affected areas, and both agencies opined that she was likely to have been infected in Singapore.

The next day, following the press announcement, SKH was tasked by the $\mathrm{MOH}$ to ringfence beds for Singapore's Infectious Diseases Hospital (Tan Tock Seng Hospital (TTSH)), as the latter's isolation ward was nearing full capacity, and would not be able to cope with the influx of the new Zika infection cases.

\section{PREPARATIONS}

SKH@AH has two closed, naturally ventilated general wards (i.e. no air-conditioning, only fans and open windows). As Zika virus is vector borne (as opposed to airborne or droplet borne, which would require a higher level of isolation facilities for patients), the Chairman, Medical Board (CMB) decided to open one of these wards to take in the Zika-positive cases from TTSH. An urgent meeting was convened on the morning of Sunday, 28 August 2016, and preparations of the ward for patients' occupation commenced that afternoon, and were completed by 13:00 hrs (GMT+8) the next morning (Monday, 29 August 2016). 
Preparations comprised infrastructure, facilities, manpower, equipment, logistics, \& supplies, communications, and screening and management procedures.

\subsection{Infrastructure}

$\mathrm{AH}$ is surrounded by ample vegetation and vector activity is abundant (refer to Fig. 1). As Zika virus is vector borne, the first order of business was to ensure that all windows were closed, air coolers were put in place, and any gaps sealed. The Environmental Services Department was also activated to clean and disinfect the ward, supply beds and mattresses, as well as linen (bed sheets and patient pajamas) for the entire ward.

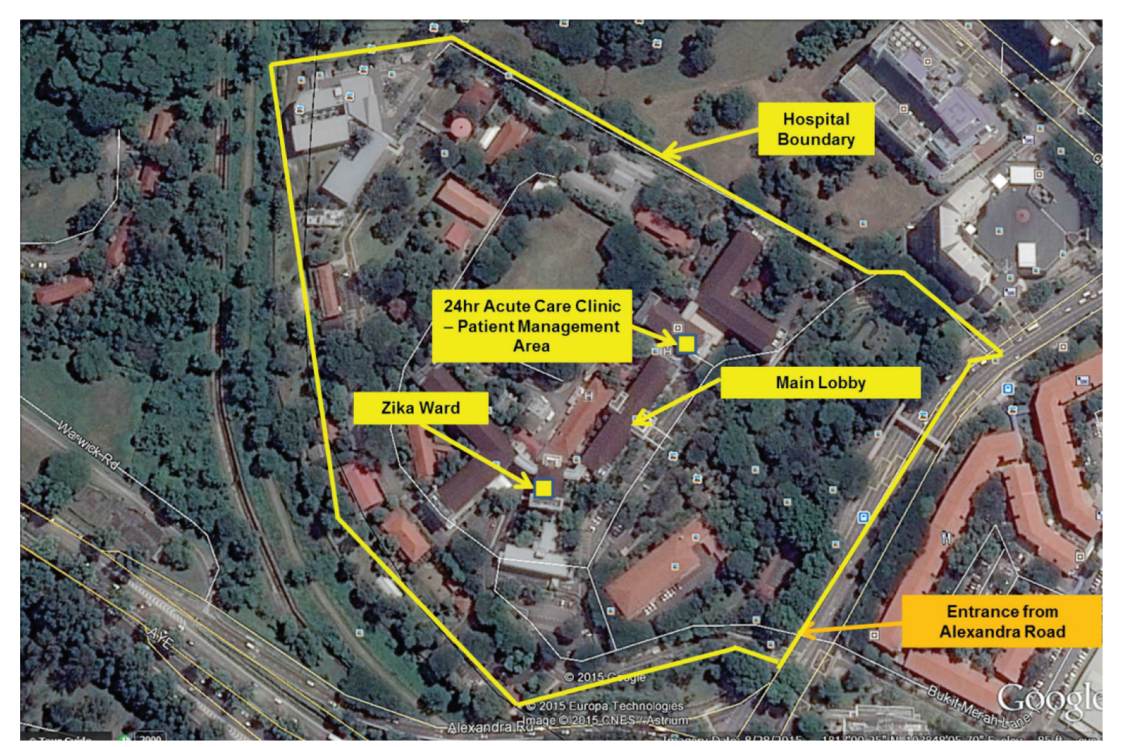

Figure 1: Satellite Image [6] of Alexandra Hospital.

These first order tasks were completed at 21:00 hrs (GMT+8) on 28 August 2016 (within nine hours of activation).

\subsection{Facilities}

The Zika ward had 35 beds, in cubicles of 5 to 6, as shown in Fig. 2. An additional 2 beds were not operationalized (bottom left of Fig. 2). There is also a patient lounge (just above the 2 unused beds) where patients could gather to watch television programmes, or play board games, which were specially provided for them, or read newspapers, or simply just mingle.

Patients were assigned beds according to sex (females nearer to the front of the ward, and males further to the back, as seen in Fig. 2). The cubicles were segregated by low partition walls (i.e. not full height walls). There are also toilets and shower facilities (also segregated by sex) within the ward. 


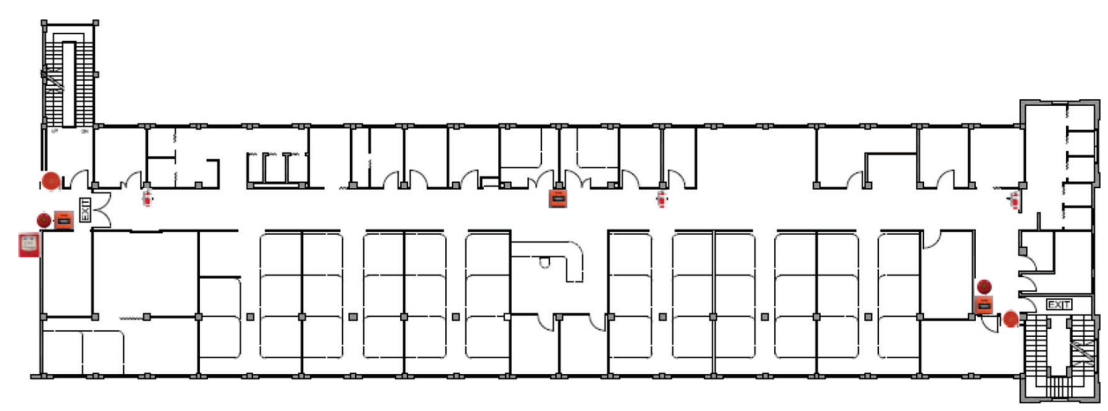

Figure 2: Layout of AH Zika ward.

\subsection{Manpower}

Nursing manpower to staff the Zika ward was drawn from the non-Zika wards. The Chief Nurse, in consultation with $\mathrm{CMB}$, decided to reduce the number of in-service beds in these non-Zika wards, so that the manpower could be deployed to man the Zika ward 24/7. Bed Management Unit, therefore, was instructed to 'fence off' these closed beds in the Bed Management System, so that patients would not be admitted to these beds accidentally.

Medical manpower (i.e. doctors) came primarily from the Division of Medicine (as opposed to Division of Surgery). The doctors were thoroughly briefed by CMB regarding the disease, and rosters were quickly arranged so that these doctors could include the Zika ward in their morning ward rounds.

The SKH Command Centre, initially manned by the Emergency Preparedness Department, was augmented by the Clinical Governance Department from the second day of operations.

\subsection{Equipment, logistics and supplies}

A separate Cost Centre was also set up within the day for staff to charge any Zika-related expenditure, in order to expedite operations, and efficiently track expenses.

Medical equipment was drawn from the store, and redeployed from other wards so that there was sufficient equipment for patients who required them.

Additionally, Information Technology (IT) equipment was deployed to the Zika ward within 24 hours of activation. These included Computers-on-Wheels (CoWs), printers, photocopier machines, etc. IT applications and software were also installed and set up within the day.

The Materials Management and Pharmacy Departments worked closely with the nursing and medical staff to provide the required drugs, pharmaceutical and medical supplies for the Zika ward. In addition, the pharmacy also procured, within 24 hours, 2000 bottles of insect repellent sprays, and an additional 1000 tubes of insect repellent cream in the next two days that followed. It is also worthy to note that the country's insect repellent suppliers and retailers ran out of insect repellents within a few days-SKH@AH was therefore one of the only hospitals to receive a substantial supply.

Environmental Services staff were rostered to collect and change the linen, and to clean the ward regularly. The pest control unit was also activated to mist the hospital premises with increased frequency (from once a week to thrice weekly) to limit vector activity. 
An insect repellent application station was set up right outside the ward, and any staff or visitors who wished to enter the ward were strongly encouraged to spray or apply the repellent cream liberally.

\subsection{Internal communications}

Things happened really quickly during the first week - the situation was fluid on the ground, and instructions from $\mathrm{MOH}$ were changing by the day. SKH management was cognizant of the need to have timely communications with the staff, and provide clear and accurate information and instructions as the situation changed. Daily bulletins to staff were instituted from the first day of operations of the Zika ward (refer to Fig. 3 for a bulletin sample).

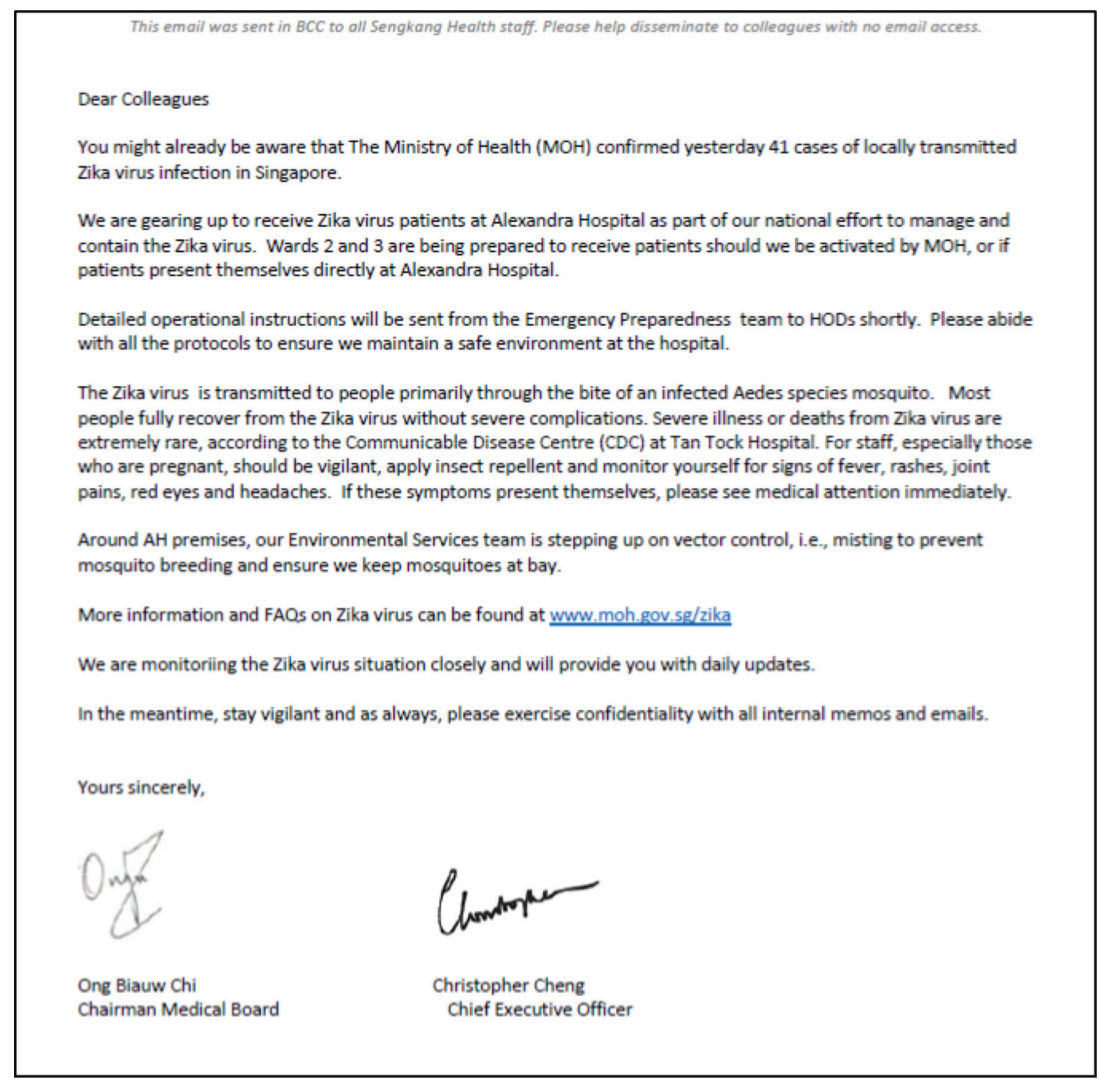

Figure 3: Snapshot of First Internal Staff Memo from the CEO and CMB.

Additionally, Operations Instructions were sent out to provide clear instructions on the workflows and situation management (refer to Fig. 4 for a sample of the first set of Ops Instructions sent out). 


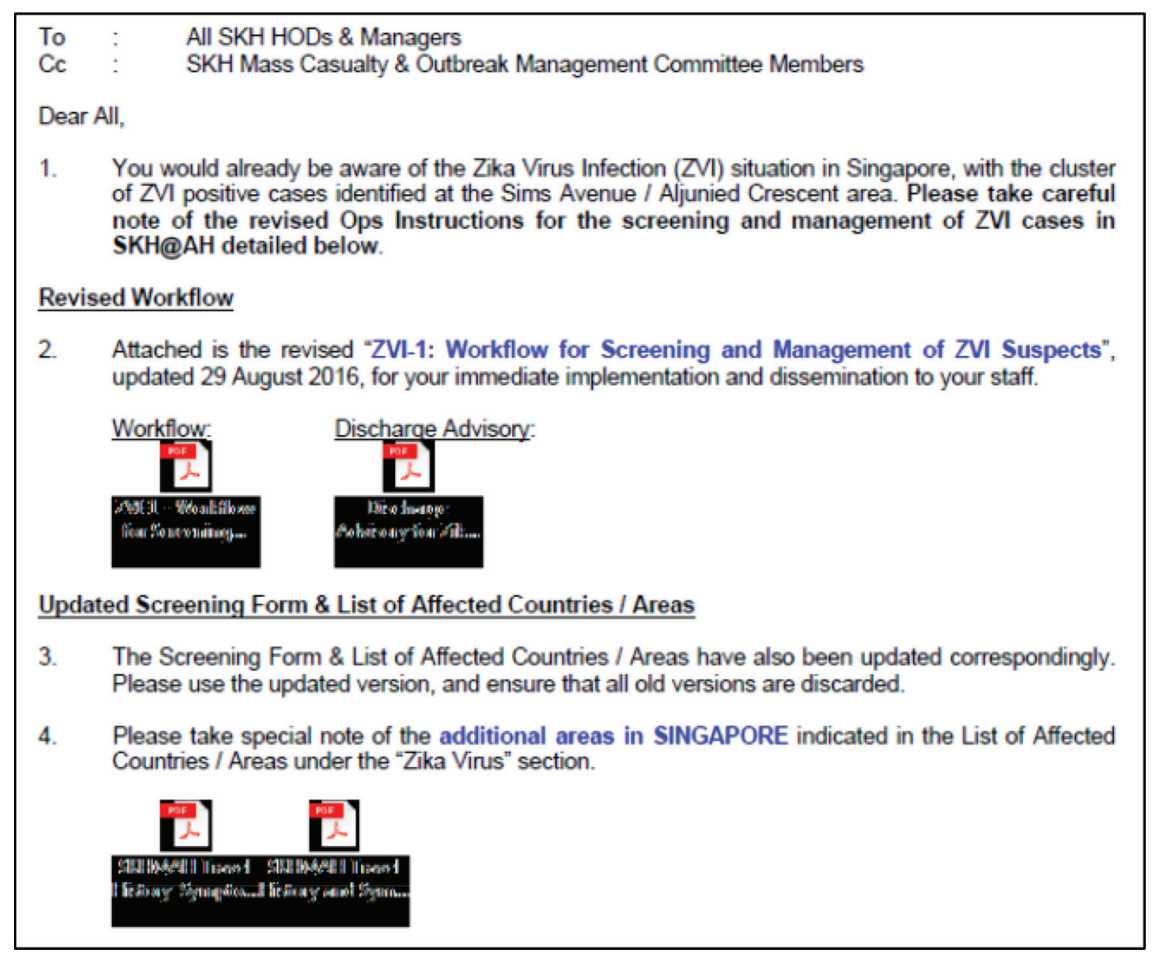

Figure 4: Snapshot of first set of operations instructions sent to the staff.

\subsection{External communications}

In a national crisis situation, communications between healthcare institutions, and with the $\mathrm{MOH}$, is critical, as coordination is key. As the situation developed, there were various avenues of information that were sometimes conflicting. Patients and their loved ones were concerned about how the virus affected them, the financial implications (tests, hospitalisation costs, etc), and generally how they could cope with the uncertainties. The press had many reports on the situation, and social media was abuzz with information and opinions. A calm and trusted voice, therefore, was critical in such a situation.

As per the standard operating procedure for such situations, all queries and correspondences with the media was fronted by the $\mathrm{MOH}$; media queries relating to specific PHIs were then directed by the $\mathrm{MOH}$ to the Communications team in such PHI respectively.

Each PHI drafted their own drawer media scripts and prepared their spokespersons for potential media queries.

\section{RECEIVING PATIENTS}

The first Zika-positive patient was transferred from TTSH to SKH@AH at approximately 21:00 hrs $(\mathrm{GMT}+8)$ the day the Zika ward was in operation. Such transfer patients had to pass through the 24hr Acute Care Clinic (ACC), where the Emergency Department doctors and nurses would assess them to ensure that their condition was stable, before allowing the ambulance staff to transfer them to the Zika ward. 
While patients arrived from TTSH and also from the Singapore General Hospital (SGH) Singapore's 1700-bedded flagship hospital - the ACC was also receiving walk-in patients who were concerned that they were infected with the virus.

SKH@AH admitted a total of 34 patients (either transferred from TTSH or SGH, or directly through the ACC) from Day 1 (29 August 2016) to Day 15 (12 September 2016), when the last patient was admitted. Table 1 below shows the breakdown of the number of patients admitted.

Table 1: Breakdown of Number of Patients Admitted to SKH@AH's Zika Ward.

\begin{tabular}{ll}
\hline Admission Date & Number of patients \\
\hline 29 August 2016 & 9 \\
30 August 2016 & 3 \\
01 September 2016 & 3 \\
02 September 2016 & 2 \\
03 September 2016 & 5 \\
04 September 2016 & 8 \\
05 September 2016 & 2 \\
08 September 2016 & 1 \\
12 September 2016 & 1 \\
Total & 34 \\
\hline
\end{tabular}

In comparison, a total of 333 cases had tested positive for the Zika virus in Singapore as of 12 September 2016. The number of confirmed cases stood at 459 as of 21 January 2017 (458 cases in 2016, and 1 case in 2017).

\subsection{Screening and management procedures}

Every patient entering the hospital system either through the ACC or the Specialist Outpatient Clinics (SOC) was screened by the frontline staff using a standard screening form (refer to Fig. 5). Those who met the case definition for Zika virus infection were then held in isolation at the ACC (as a precaution, because as mentioned earlier, SKH@ $\mathrm{AH}$ is surrounded by greenery and vector activity is abound), while their blood and urine samples were drawn and sent to the laboratory to be tested for the presence of the virus.

Patients found to be positive were then admitted to the Zika ward. Those that were found to be negative were then discharged with the necessary medications and documentations.

On 05 September 2016, the MOH issued a press release [7] that the Ministry no longer required suspect cases to be isolated. This signalled the transition from what the Ministry terms the 'Containment Phase' to the 'Mitigation Phase', and was an acknowledgement that the virus was now widespread in the community.

Laboratory testing was now no longer mandatory for all patients presenting with symptoms, and patients could wait for their test results at home. Patients who tested positive for the virus need not be hospitalised unless clinically required, and those who were admitted did not require isolation. 


\begin{tabular}{l|l|} 
LOCATION: & $\begin{array}{l}\text { Affix Patient Sticky Label if available } \\
\text { NAME: } \\
\text { NRIC / PASSPORT NO.: }\end{array}$ \\
\hline
\end{tabular}

Date:

Patient's Mobile No:

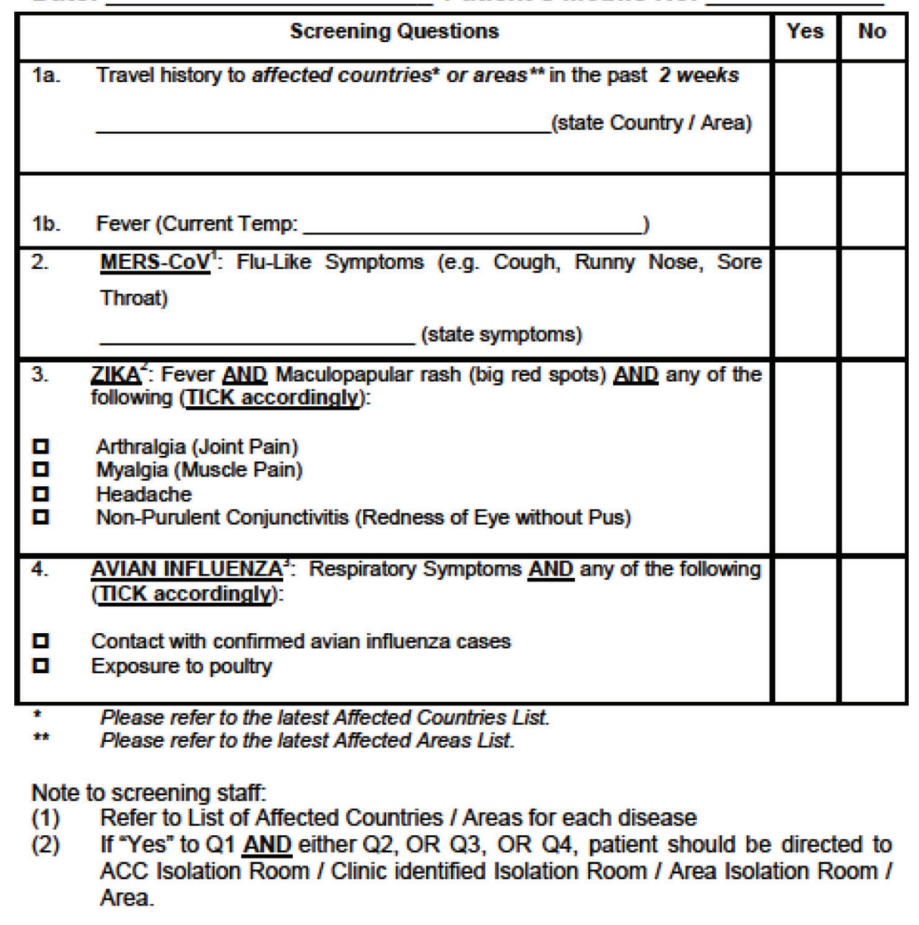

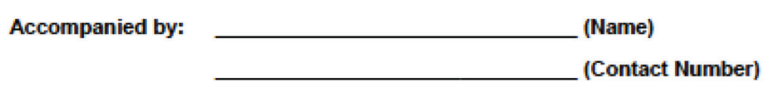

Screening done by:

Screening Form Revised on 29 August 2016

Page 1 of 1

Figure 5: Snapshot of SKH@AH Travel History \& Symptoms Screening Form.

With this announcement, from 06 September 2016 onwards, Singapore stepped down its heightened alert, but operationally, vector control measures continued to be the cornerstone of the National Environment Agency's and MOH's strategy to limit the spread of the disease. This was also translated down to the PHIs.

\subsection{Types of patients presenting at the Hospital's 24 hr Acute Care Clinic}

Patients presenting at the ACC (either transferred cases from SGH and TTSH, or individuals coming on their own to SKH@AH) were generally well. No pregnant patients presented at 
the hospital. Some of the patients presented only with fever, some with rashes, and many were actually asymptomatic. At the beginning of the episode, these patients were judiciously tested for the virus if they stayed within the identified clusters' areas (Aljunied at first, and other areas subsequently). With the stepping down of the alert level, tests were only done if the physician felt that it was clinically required.

\subsection{Stepping down of measures and closure of the zika ward}

There were 11 patients remaining in the Zika ward on the morning of 04 September 2016, and the laboratory results for 10 of them came back negative. The sole remaining patient who could not be discharged would be transferred to a General Ward. Instructions were therefore issued from the SKH Command Centre (after discussion with $\mathrm{CMB}$ ) to close the Zika ward, and for all future Zika positive cases to be admitted to the Isolation Ward, more for ease of management than for the requirement to isolate them, as the Isolation ward was situated just next to the ACC. The MOH was also informed of this decision.

\section{AFTER ACTION REVIEW}

An After Action Review (AAR) for the management of the episode was conducted on 16 September 2016. This helped identify key best practices, challenges faced, and areas for improvement.

\subsection{Key challenges and learning points}

The two main challenges presented by the management of the Zika virus were: (1) the disease was relatively unknown, and there appeared inconclusive and insufficient research on the subject. Patients and staff were therefore concerned about how the disease would affect them, and (2) as the situation was fluid on the ground, guidelines and instructions from the $\mathrm{MOH}$ were constantly changing, and sometimes could not be absolutely clear. This sometimes resulted in difficulties in disseminating accurate and timely information to the ground.

With close and constant communications between the senior management and the staff on the ground, as well as an appointed single source of instructions and information (SKH Command Centre), however, the staff were kept abreast of new developments, and were thus able to manage the patients' and next-of-kins' expectations.

\subsection{Areas for improvement}

As with all crises, there are areas that could be improved upon. These included: (1) the requirement for a Hospital Operations Centre or Command Centre to coordinate and manage crises, (2) the need to leverage on information technology for speedy collation and collection of data, and timely dissemination of critical information to key stakeholders, (3) the need for clarity on financial guidelines as early as possible, because patients were clearly concerned about this, and (4) the opportunity for Standard Operating Procedures to be set in place, so that future similar situations could be better managed.

\section{CONCLUSION}

In conclusion, communications is critical in the management of any crisis, and a single source of information and instructions is important to ensure that there is no confusion or conflicting 
directions to the ground. SKH was able to manage this episode relatively effortlessly because the senior management understood this.

\section{REFERENCES}

[1] Hospital Services. Ministry of Health Website, Singapore, available at www.moh.gov. sg/content/moh_web/home/our_healthcare_system/Healthcare_Services/Hospitals. html (accessed 03 January 2017)

[2] It's matter of time before Zika virus hits Singapore: Potential threat for pregnant women. The Asian Parent Website, Singapore, available at https://sg.theasianparent.com/ zika-virus/ (accessed 20 January 2017)

[3] 'Matter of time' before Zika cases are seen in Singapore: Experts. Channel News Asia Website, Singapore, available at http://www.channelnewsasia.com/news/singapore/ matter-of-time-before/2481498.html (accessed 20 January 2017)

[4] First Case of Locally Transmitted Zika Virus Infection. Ministry of Health Website, Singapore, available at www.moh.gov.sg/content/moh_web/home/pressRoom/pressRoomItemRelease/2016/first-case-of-locally-transmitted-zika-virus-infection.html (accessed 03 January 2017)

[5] First case of locally-transmitted Zika virus infection reported in Singapore: $\mathrm{MOH}$, NEA. Channel News Asia Website, Singapore, available at www.channelnewsasia.com/ news/singapore/first-case-of-locally/3078974.html (accessed 03 January 2017)

[6] Satellite Image of Alexandra Hospital. Google Maps, available at https://www.google. com.sg/maps/place/Alexandra+Hospital/@ 1.2866021,103.7988575,687m/data=!3m2! 1e3!4b1!4m5!3m4!1s0x31da1bcb19f367f5:0x8f256e299bf58c73!8m2!3d1.2866021!4 d103.8010462!6m1!1e1 (accessed 13 January 2017)

[7] Cessation of Isolation, MOH to Subsidize Zika Testing for all Singaporeans with Symptoms. MOH Ministry of Health Website, Singapore, available at https://www.moh.gov. sg/content/moh_web/home/pressRoom/pressRoomItemRelease/2016/cessation-of-isolation--moh-to-subsidise-zika-testing-for-all-si.html (accessed 02 February 2017) 